\title{
Pilonidal Disease
}

\author{
Amit Khanna, M.D. ${ }^{1}$ and John L. Rombeau, M.D. ${ }^{1}$
}

\section{ABSTRACT}

Pilonidal disease presents many therapeutic challenges to surgeons throughout the world. Its varied clinical presentations necessitate a wide range of treatments, thus underscoring the need to tailor the treatment to the patient and the severity of disease. Recent studies confirm the efficacy of smaller, more conservative operations for appropriate indications. When flap closures are performed, every attempt should be directed to placing sutures off (lateral) to the midline gluteal cleft. Meticulous attention to the details of immediate and long-term postoperative care is paramount.

KEYWORDS: Pilonidal disease, abscess, Bascom cleft lift, Karydakis flap

Objectives: On completion of this article, the reader should be able to summarize the operative and nonoperative treatments for acute and chronic pilonidal disease.

Pilonidal disease is a common source of morbidity and loss of work productivity in healthy young adults, thus, the importance of its operative treatment and postoperative care. In this article, we examine current evidence regarding the etiology, pathogenesis, and surgical management of pilonidal disease. Conclusions from recent reports of surgical treatments are reviewed. Finally, adjunctive measures to improve local wound healing are discussed.

\section{BACKGROUND AND INCIDENCE}

Pilonidal disease is an infection under the skin in the gluteal cleft. Pilonidal literally means a "nest of hair." It affects an estimated 26 per 100,000 persons, ${ }^{1}$ occurring primarily in young adults with a 3:1 male predilection. Known risk factors include family history, local trauma, sedentary occupation, and obesity. ${ }^{2}$

Herbert Mayo is credited with the first description of this disease in $1833,{ }^{3}$ and Hodges coined the term pilonidal in $1880 .^{4}$ Buie noted its prevalence in male, military recruits who drove jeeps and thus characterized it as "jeep disease." Pilonidal disease was most notable during World War II when an estimated 80,000 soldiers became afflicted and lost significant time from active duty. ${ }^{5}$

\section{ETIOLOGY}

The disease was initially thought to be congenital, due to the failure of fusion in the dorsal midline resulting in entrapment of hair follicles in the sacrococcygeal region; however, more recent research strongly favors an acquired etiology.

Several findings support an acquired etiology. Occupation may play a role. Interestingly, pilonidal disease has been reported to occur between the fingers of sheep shearers, dog groomers, cow milkers, and barbers. ${ }^{6}$ The acquired theory is further supported by Bascom who notes that hair follicles in the gluteal cleft
${ }^{1}$ Department of Surgery, Temple University Hospital, Temple University School of Medicine, Philadelphia, Pennsylvania. Address for correspondence and reprint requests: John L. Rombeau, M.D., Department of Surgery, Temple University Hospital, Temple University School of Medicine, 3401 N. Broad St., 4 Parkinson/Zone C, Philadelphia, PA 19140 (e-mail: john.rombeau@ tuhs.temple.edu).
Anorectal Disease; Guest Editor, Gerald A. Isenberg, M.D.

Clin Colon Rectal Surg 2011;24:46-53. Copyright (C) 2011 by Thieme Medical Publishers, Inc., 333 Seventh Avenue, New York, NY 10001, USA. Tel: +1(212) 584-4662.

DOI: http://dx.doi.org/10.1055/s-0031-1272823.

ISSN 1531-0043. 


\section{Table 1 Formation of Pilonidal Sinus}

- A midline pit develops that may be a hair follicle, which has shed its own hair and then allows debris to occupy the pit.

- Loose semicurved roots of hair fall and migrate to the cleft where they become vertically oriented and insert into the pit via their roots.

- A foreign body granuloma develops in the subcutaneous fat.

- The depth of the natal cleft is associated with anaerobic environment with moisture and pressure that can lead to increased hair insertion.

- The direction of the follicle determines the direction of the tract.

Adapted from Kitchen. ${ }^{10}$

become infected with keratin resulting in local infection and abscess formation while local suction forces cause hairs to enter the infected pit and lodge in the abscess cavity. ${ }^{7}$ Karydakis asserts that loose hairs "impale" into otherwise normal tissue and induce a foreign body reaction. Secondary pits then result from subcutaneous burrowing of hair and additional hairs enter through the pits. ${ }^{8}$ His work in over 6000 patients led him to devise a pathogenic formula involving three primary variables: (1) loose hair or "invader" $(\mathrm{H})$ applies some (2) force (F), which is influenced by secondary factors such as the depth, narrowness, and friction of the natal cleft to create an insertion process. The third factor of vulnerability, $(V)$, refers to the local skin and tissues. In this model the primary sinuses represent the hair entry sites and secondary sinuses represent the exit points. ${ }^{9}$

$$
\begin{aligned}
& \text { Pilonidal Disease }=\text { Hair }(\mathrm{H}) \times \text { Force }(\mathrm{F}) \\
& \times \operatorname{Vulnerability}(\mathrm{V})^{2}
\end{aligned}
$$

Kitchen outlined a sequence of factors, as shown in Table 1, that describe the formation of a pilonidal sinus. ${ }^{10}$ Additionally, the depth of the natal cleft is a developmental factor. Akinci and colleagues studied 50 patients undergoing surgery for pilonidal disease and 51 healthy volunteers who had their natal clefts measured with a specially designed device. They observed significantly deeper natal clefts in patients with pilonidal disease. ${ }^{11}$

\section{PATHOLOGY}

Although often described incorrectly as a cyst, pilonidal cavities are not true cysts and lack a fully epithelialized lining; however, the fibrous tracts of the sinus may be epithelialized. Pilonidal sinus or disease is therefore the correct term. The majority of sinus tracts extend cephalad; however, additional sinuses may branch laterally. Interestingly, hair follicles are rarely seen on pathologic examination. Cavities may contain hair, debris, and granulation tissue. The local cellular infiltration is sizable and often includes foreign body giant cells in association with hair. ${ }^{12}$

\section{CLINICAL PRESENTATION}

The initial clinical presentation varies. Acute pilonidal abscess presents similarly to localized, superficial abscesses in other locations. Chronic abscess cavities often appear with retained hair and frequently include chronically draining sinuses.

The differential diagnosis of pilonidal disease includes anorectal crytoglandular abscess extending into the natal cleft, hidradenitis, and low anorectal fistula such as seen in Crohn's disease. A digital rectal examination with a rigid proctoscopy should therefore be performed prior to operating upon a patient for pilonidal disease. Although there are various stages of disease progression, for discussion purposes, clinical presentation can be divided into acute and chronic disease.

\section{Acute Pilonidal Abscess}

Most patients present initially with pain, tenderness, swelling, and erythema in the gluteal cleft with or without drainage from the involved area. Primary pits may be visible in the midline of the gluteal cleft; however, they are often obscured. If observed, the diagnosis of pilonidal disease is supported. Secondary tracts or pits off the midline occur with multiple complex sinuses leading to secondary openings.

\section{Chronic Pilonidal Abscess/Draining Sinus Tracts}

This condition is essentially a chronic pilonidal sinus cavity with recurrent drainage due to retained hair and infected residue. It may be difficult to recognize the sinus pits in the presence of acute inflammation and swelling.

Regardless of whether abscess is acute or chronic, it should be drained with an incision at least 1 to $2 \mathrm{~cm}$ lateral to the intergluteal cleft (Fig. 1).

\section{TREATMENT STRATEGIES}

The choice of ideal therapy should be guided by several principles (Table 2), tailored to the patient and the extent of the disease. Regrettably, no single treatment fulfills all of these requirements. The projected rate of recurrence and anticipated return to work and normal physical activity are important determinants in operative selection. Both nonoperative and operative treatments are efficacious in appropriate settings.

\section{Nonoperative Treatment}

\section{SHAVING/DEPILATION}

The preventive and therapeutic importance of shaving hair surrounding the gluteal cleft has been emphasized in many reports ${ }^{13-15}$; however, the optimal frequency of 


\section{Table 2 Principles for Treatment of Pilonidal Disease}

- Simple to perform

- Limited inpatient stay

- Low recurrence rate

- Minimal postoperative pain

- Limited wound care

- Early return to activity

- Cost effective

shaving is unclear. A 3- to 4-cm area around the diseased segment should be shaved. A prudent approach is to shave until complete healing has occurred. In a military study, simple shaving and removing of external hairs from the sinus resulted in healing of all 101 patients. ${ }^{16}$

Laser depilation has been investigated as a possible adjunct to pilonidal disease surgery. The use of this treatment was reported in 14 patients with recurrent pilonidal disease. ${ }^{17}$ Four individuals required repeat therapy. All patients reported improvement in their disease, but pain was a significant disadvantage.

\section{Operative Treatment}

\section{MINIMAL/MODERATE DISEASE}

Surgical strategies include incision and drainage, unroofing and open secondary healing, incision with mar-

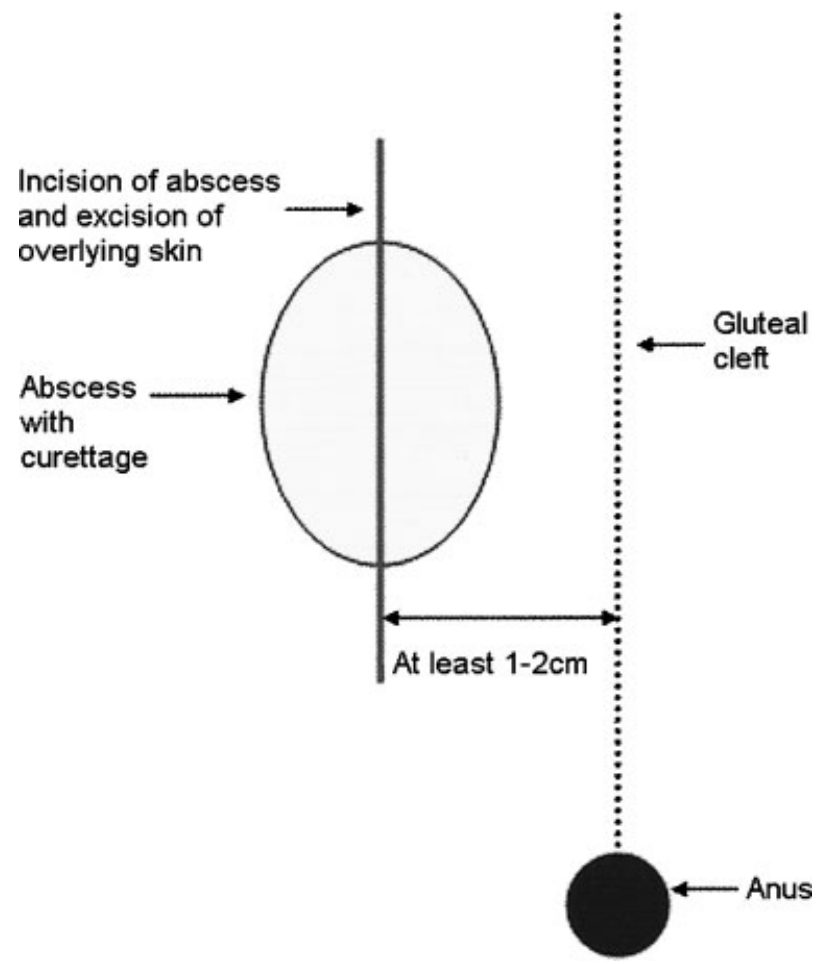

Figure 1 Off-midline incision and drainage of pilonidal abscess. Lateral incision for drainage is made even when the abscess is primarily in the midline. Modified from Nelson and Billingham. ${ }^{18}$ supialization, Bascom chronic abscess curettage with midline pit excision, and in some instances, primary closure with flap procedures.

\section{INCISION AND DRAINAGE}

A limited off-midline incision is combined with excising a small ellipse of overlying skin to promote drainage (see Fig. 1). Removal of associated hair and debris with curettage in the diseased cavity are performed concurrently. If complete healing does not occur, similar procedures can be performed after the acute inflammation subsides.

The value of using methylene blue to identify associated sinus tracts is variable. Some authors note that it does not completely diffuse through the tracts due to semisolid material obstructing the path of the dye. Da Silva cites the unreliability of marking dyes that results in overaggressive resection of affected tissues. He suggests frequent recurrences may be due to overreliance on dye staining the secondary tracts. ${ }^{12}$

\section{UNROOFING AND OPEN SECONDARY HEALING}

Excision of midline tracts followed by an open wound leads to prolonged healing. Unroofing of the tracts minimizes the midline wound and shortens healing accordingly. This approach is effective in the presence of a concomitant abscess. Recurrence has been reported to be less than $13 \%$ with this technique. ${ }^{18}$

\section{INCISION WITH MARSUPIALIZATION}

This approach involves opening the sinus tracts in the midline to include any secondary tracts. The posterior and lateral fibrous tissue is then left in situ and sutured to the skin edge or dermis. The goal is to reduce the effective wound healing area thus reducing the time of healing.

Solla and Rothenberger reported 150 patients in which $83 \%$ underwent marsupialization and had a recurrence rate of $\sim 6 \%{ }^{13}$ Several studies have evaluated the effectiveness of incision with marsupialization when compared with excisional therapy. Karayakalli concluded that although healing time and postoperative care was longer in patients with marsupialization, other factors such as quality of life, return to work time, and pain scores were favored in unroofing and marsupialization when compared with excisional therapy followed by flap closure. $^{19}$

\section{BASCOM CHRONIC ABSCESS CURETTAGE WITH MIDLINE PIT EXCISION (BASCOM I)}

Bascom designed an operation based on the hypothesis that the hair follicle itself, not the hair shaft, was the source of local sepsis. Midline pits are conservatively excised with removal of contiguous hair and debris in the pits (Fig. 2). The use of trephines and disposable dermatologic punch biopsy instruments $(2-3 \mathrm{~mm}$, our 

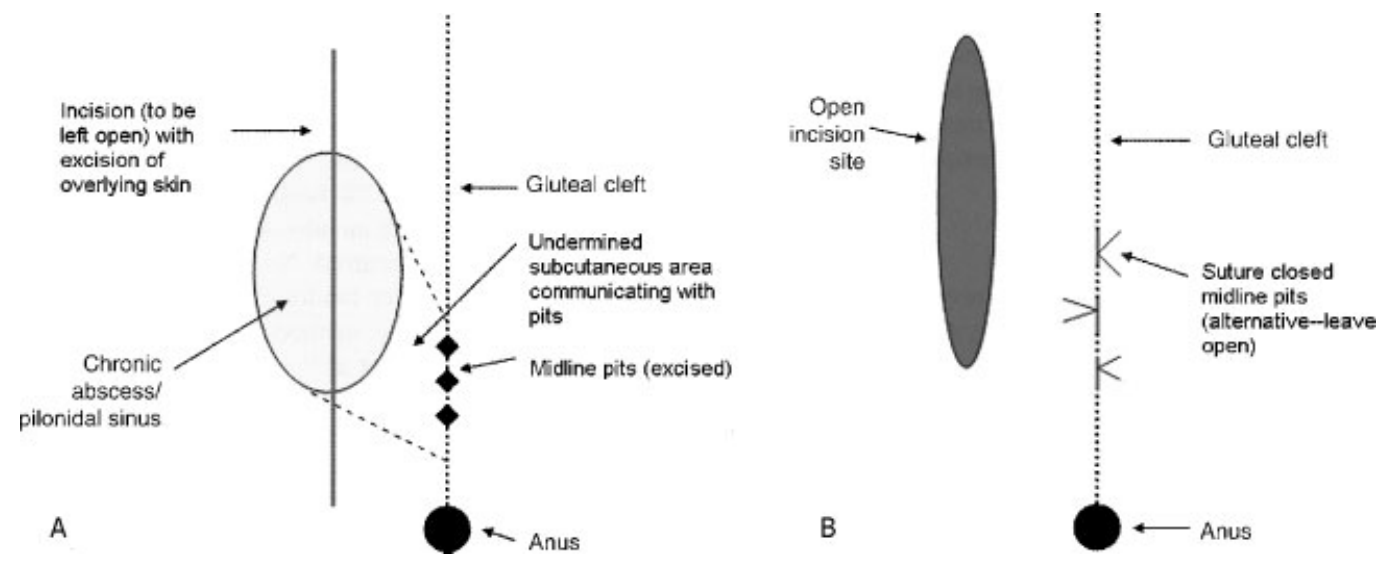

Figure 2 (A) Bascom lateral drainage. (B) Subcutaneous undermining and excision of sinus pits. Modified from Nelson and Billingham. ${ }^{18}$

preference) (Fig. 3) is an excellent method to excise the infected, epithelialized sinus pit, while still minimizing the extent of the midline wound. ${ }^{20} \mathrm{~A}$ concomitant lateral incision, parallel to the midline wound, is made to curette the debris from the cavity connecting the sinus pits. All incisions are usually left open to heal by secondary intention. Wounds are followed closely to remove hair that may gravitate into the wound. Careful and frequent wound care is essential for the success of this technique. This care is optimally provided in an office equipped with proper lighting and a proctoscopic table for optimal exposure. In our experience, reliance upon visiting nurses or family members to provide wound care is unsatisfactory. Bascom reported 161 patients with a follow-up period of over 3 years had a $16 \%$ recurrence rate and a healing time of approximately 3 weeks. ${ }^{21,22}$

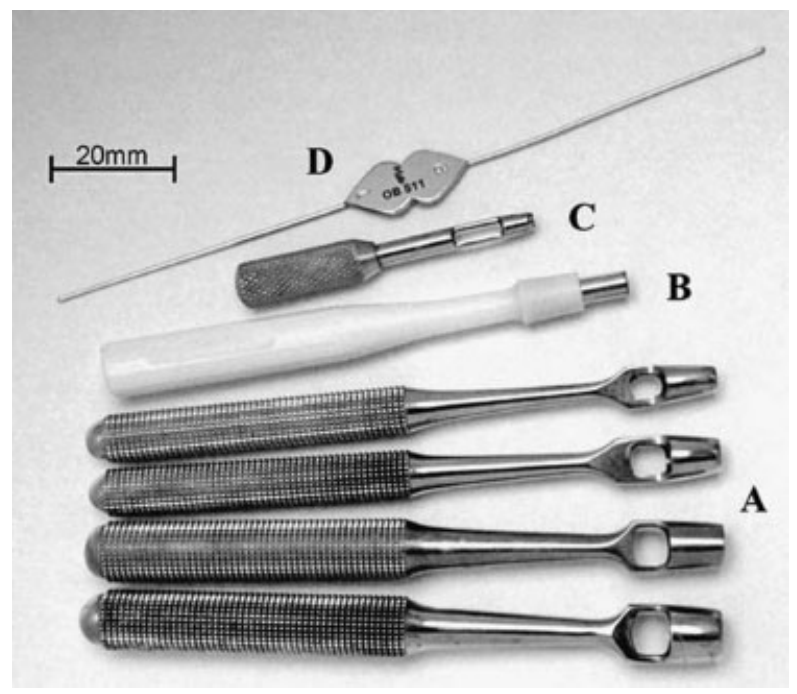

Figure 3 (A) Keyes trephines of various diameters. (B) Disposable punch. (C) Ophthalmic Searcy trephine. (D) Thin lacrimal 0/00 probe. From Gips et al. ${ }^{20}$ With permission from Wolters Kluwer Health.
Using Bascom's approach, Senapati reviewed over 200 patients with a $90 \%$ success rate at one year. ${ }^{23}$ Gips reviewed 1358 patients using office-based trephines to excise and debride the pilonidal tracts leaving skin bridges in between primary and secondary tracts intact as described previously. ${ }^{20}$ Patients were followed weekly or biweekly with shaving and additional debridements as indicated. The disease-free probability estimate was $93.5 \%$ at one year and $86 \%$ at 5 years.

\section{Severe and Recurrent Disease}

Despite well-intended and frequently performed conservative approaches to control initial disease, recurrent infections remain a serious problem. These are often treated with excision and flap closure. Evidence continues to support flap closure off the midline, particularly as to reducing the time of healing. ${ }^{24}$ The negative aspects of flap closures are more prolonged operative time, greater blood loss, and potential infection with loss of the flap. The following includes a brief summary of commonly performed flap procedures. A complete description of operative techniques is beyond the scope of this report.

\section{KARYDAKIS FLAP}

The Karydakis flap was designed to create an off-midline closure by performing a sliding type flap with an oblique excision of the pilonidal sinus close to the level of the presacral fascia. The goals of the procedure are to flatten the natal cleft and take the wound off the midline (Fig. 4). In the Karydakis series, less than $1 \%$ of over 5000 patients, followed over 20 years, developed recurrence. The wound complication rate approximated 9\%. ${ }^{9}$

\section{BASCOM CLEFT LIFT (BASCOM II)}

Bascom cleft lift closure involves excision of the underlying, unhealed skin and sinus tracts. A full thickness skin flap is mobilized across the gluteal cleft to create an 

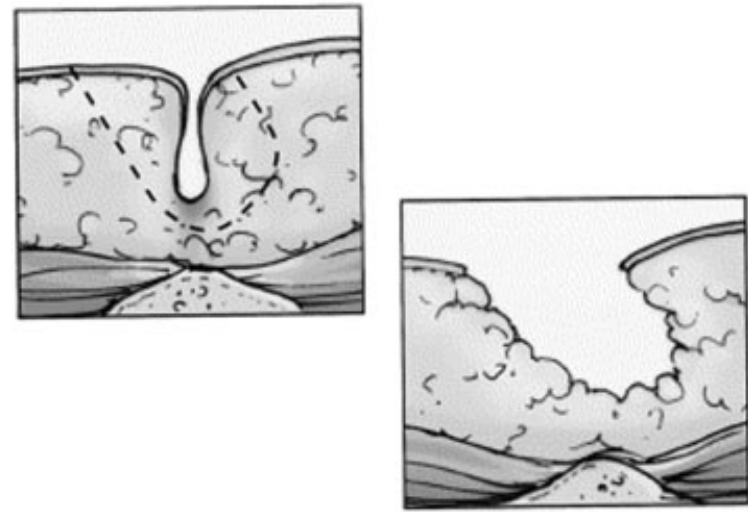

Figure 4 Excision of the disease and primary closure is one surgical option. In an effort to improve upon this technique, Karydakis modified the procedure. The midline sinus is excised elliptically and the wound closed lateral to the midline. To do this, a thick flap is created by undercutting the medial wound edge and advancing it across the midline. By doing this, the natal cleft is flattened and the entire suture line is positioned lateral to the midline. From Hull and Wu. ${ }^{15}$ With permission from Elsevier.

off-midline closure (Fig. 5). The goal of this procedure is to completely eliminate the gluteal cleft in the diseased area. The gluteal fat is allowed to appose and excess skin is excised to re-contour the natal cleft and allow a shallower closure away from the midline. Its main differences, when compared with the Karydakis flap, are the lack of excision and mobilization of the fatty subcutaneous tissues and the reliance upon skin flaps. If present, the remaining open sinus tracts and chronic wounds are curetted and not excised. The remaining suture line for flap closure is well off the midline and should be tension free. Bascom reported complete wound closure with the cleft lift procedure in 30 patients who previously had failures with other operations. There was only one recurrence at 2 years. ${ }^{25}$

\section{RHOMBOID EXCISION WITH LIMBERG/MODIFIED LIMBERG FLAP}

A lateral advancement flap can be combined with a rhomboid type excision and rotational advancement flap. A rhomboid excision of the skin and soft tissues surrounding the sinus are excised to the level of the sacral periosteum. The gluteal fascia is then mobilized on its inferior edge laterally to allow a rotational tension-free flap to cover the rhomboid excision. This full thickness flap is generally closed with a suction draining system postoperatively. Common complications are seroma and wound separation.

Modifications to this classic technique, ascribed to Limberg, have been adapted by some authors to attempt to reduce recurrent disease, particularly at the inferior apex of the wound. The inferior end of the rhomboid excision is made 1 to $2 \mathrm{~cm}$ lateral to the midline on the nondonor tissue side. This technique results in greater flattening of the natal cleft. ${ }^{26}$ Cihan et al reviewed this modification of the classic Limberg approach in 68 patients and found a significant reduction in early failures at a follow-up of 29 months. ${ }^{27}$

In 2008, Mahdy et al reported 60 patients treated with classic Limberg, modified Limberg, or adipofasciocutaneous flap. ${ }^{26}$ The latter technique was based on a medially advanced rectangular advancement flap after a
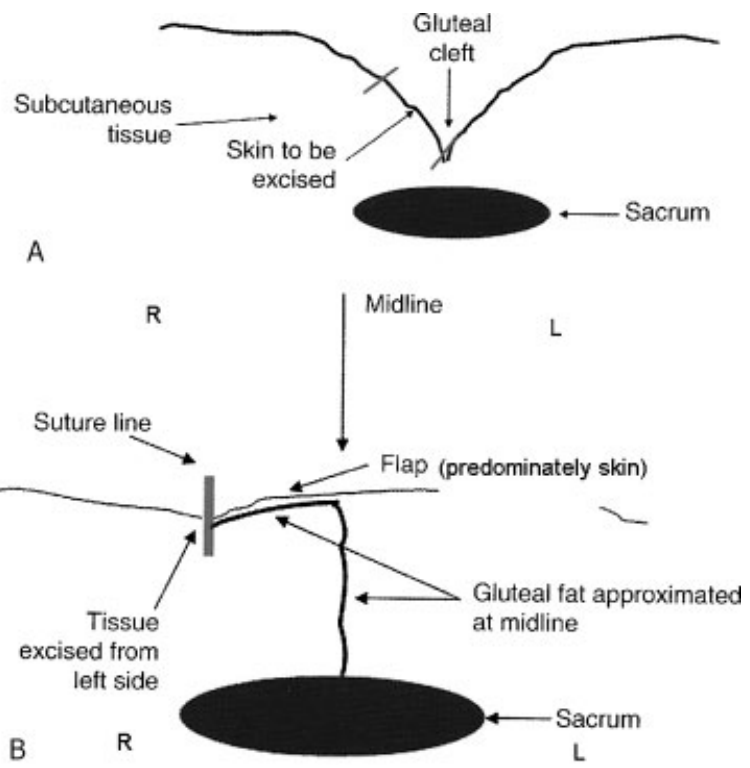

Figure 5 (A) Cleft lift technique as described by Bascom (Bascom II) for nonhealing midline wounds. (B) Final result after flap is raised and underlying gluteal fat is approximated. Modified from Nelson and Billingham. ${ }^{18}$ 
full-thickness rectangular excision was performed. The authors found no recurrence, wound infections, or wound breakdown in the modified Limberg flap group after a mean follow-up of 21 months. Mentes et al also reviewed 353 patients in the Turkish military who underwent classic Limberg flap closure over 24 months with a recurrence rate of $3.1 \%{ }^{28}$

\section{V-Y ADVANCEMENT FLAP}

$\mathrm{V}-\mathrm{Y}$ advancement flaps involve excision of the sinus combined with a full-thickness flap in the shape of a $\mathrm{V}$ with the ultimate postrepair suture line giving the appearance of a $\mathrm{Y}$ after the flap harvest and defect are closed. V-Y advancement flaps were investigated in a randomized, prospective study by Nursal and colleagues of 238 patients with chronic pilonidal disease. ${ }^{29}$ Patients were assigned to one of three groups: (1) excision and primary closure with single-layer skin and subcutaneous tissue closure, (2) a two-layer closure using a deep subcutaneous closure and a skin closure, and (3) a V-Y advancement flap. There were no significant differences in postoperative complications, disease recurrence, and patient satisfaction among groups. It was concluded that $\mathrm{V}-\mathrm{Y}$ flaps were not superior to primary closure techniques.

\section{Z-PLASTY}

Z-plasty has been adapted to the treatment of pilonidal disease and involves creating incisions in a 30-degree angle to the long axis of the wound to alter the depression of the natal cleft and allow primary closure. Subcutaneous flaps are then raised and transposed to close the excised defect. Using a randomized approach, 72 patients were assigned to either excision and curettage or Z-plasty in a recent review by Fazeli. ${ }^{30}$ Wounds healed significantly faster in the Z-plasty group (15 vs 41 days, $p<0.001)$ and the conventional surgery group took longer to recover normal activities (17.5 vs 11.9 days, $p<0.001$ ). There were no significant differences in bleeding, hematoma, infection, or recurrence between groups during the 22-month follow up period and hospitalization period was longer in the Z-plasty group.

\section{GLUTEUS MAXIMUS MYOCUTANEOUS FLAP}

Gluteus maximus myocutaneous flaps have been used in patients with extensive, recurrent, and complex disease. This procedure involves the mobilization of the gluteus maximus muscle to cover the excised defect. The assistance of an experienced plastic surgeon is often helpful. This flap is a large, well-vascularized flap that has the potential to fill large defects. Of concern is the potential for significant morbidity if wound complications occur. Additionally, this approach is associated with a significant hospital stay and limited short-term mobility.

\section{COMPARISONS OF PRIMARY CLOSURE VS} OPEN HEALING

A 2010 Cochrane Review of randomized, controlled trials (RCT) compared wound healing in pilonidal patients treated with surgical excision with primary closure versus healing by secondary intention. ${ }^{24}$ Exclusion criteria were non-RCT, children aged younger than 14 years, and studies of pilonidal abscess. No distinction was made between new (initial presentation of the disease) and recurrent presentation of pilonidal sinus disease. Eight additional trials were added to the previous Cochrane Review ${ }^{31}$ giving a total of 26 studies $(n=2530)$. Seventeen studies compared open-wound healing with surgical closure. Surgical site infections (SSI) rates did not differ significantly between treatments; recurrence rates were lower in open healing than primary closure (RR, 0.60; 95\% CI, 0.42-0.87). Six studies compared surgical midline with off-midline closure. Healing times were more rapid after off-midline closure (MD, 5.4 days; 95\% CI, 2.3-8.5). SSI were significantly higher after midline closure (RR, 3.72; 95\% CI, 1.86-7.42) and recurrence rates were higher after midline closure (Peto OR, 4.54; 95\% CI, 2.308.96). The authors concluded there was no clear benefit for open healing over surgical closure. A clear benefit was shown for off-midline when compared with midline when closure of excised pilonidal sinuses is the desired option.

\section{POSTOPERATIVE MANAGEMENT AND ADJUNCTIVE THERAPY}

\section{Antibiotics}

The value of perioperative antibiotics has been investigated. The routine use of preoperative antibiotics in a prophylactic role is unproven. Sondenaa et al evaluated the role of perioperative antibiotics using intravenous cefoxitin versus no antibiotic in 153 patients undergoing excision with primary closure and found no significant differences in postoperative wound infections. ${ }^{32} \mathrm{Simi}^{-}$ larly, the efficacy of either oral or topical antibiotics in the postoperative period has not been clearly established in the absence of immunodeficiency, associated cellulitis, or concurrent systemic illness. ${ }^{33}$ In summary, the routine use of perioperative antibiotics is unsupported. We restrict the use of antibiotics to the presence of associated cellulitis.

\section{EXPERIMENTAL TREATMENTS}

\section{Phenol}

The therapeutic efficacy of phenol injections (80\% phenol liquid application) has been investigated. Their use has been somewhat limited due to their side effects of 
severe inflammation and significant pain. The intraoperative use of a different type of phenol compound, crystallized injections, has been recently investigated. ${ }^{34}$ The sinus opening was enlarged to allow hair and debris to be thoroughly cleaned, prior to crystal phenol application with local anesthetic. The anus was protected with a swab, while a protective ointment was applied to the adjacent skin. Crystallized phenol was applied for $\sim 2$ minutes and then manually drained from the sinus. The success rate was $95 \%$; however, the mean recovery time was 42.7 ( \pm 24 days). The authors also noted that neither the presence of an abscess nor the number of sinus openings adversely influenced the beneficial effects of the phenol. More recently, Aygen and colleagues reviewed 36 patients with recurrent, postoperative pilonidal disease who were treated nonoperatively with crystallized phenol. ${ }^{35}$ The recurrence rate was $13.9 \%$ at 54 months and the overall success rate was $91.7 \%$.

\section{Platelet-Rich Plasma}

Platelet-rich plasma contains growth factors such as platelet-derived growth factor (PDGF), vascular endothelial growth factor (VEGF), epidermal growth factor (EGF), connective tissue growth factor (FGF), and transforming growth factor $\beta$ (TGF- $\beta$ 1,2,3), all of which mediate wound healing. ${ }^{36,37}$ Spyridakis prospectively investigated 52 patients who underwent excisional therapy with open secondary closure. ${ }^{38}$ Patients were randomized to platelet concentrate thrombin mixture to the wound or no therapy. Wound healing rates were 24 versus 30 days in favor of the treated group. Improved quality of life and earlier return to activity were also noted in this treatment group.

\section{Vacuum-Assisted Closure}

The efficacy of vacuum-assisted closure (VAC) has been examined in patients with large operative defects. Reepithelialization of the tissue at 8 weeks was reported with the use of a VAC on a pilonidal disease patient with a large defect from complex disease. ${ }^{39}$ Lynch and colleagues reviewed three cases in which the authors used a VAC with negative pressure of $50 \mathrm{~mm} \mathrm{Hg} .{ }^{40}$ Two of the cases required skin grafts; the third healed without further intervention. The role of vacuum-assist devices for large defects in patients at high risk for flap closure deserves further study.

\section{CONCLUSIONS}

Pilonidal disease continues to present many therapeutic challenges. Treatment must be adapted to the extent and severity of disease. Evidence supports both open and closed operative approaches with no major differences in complication rates. Open approaches with limited sinus excision are effective for patients with limited disease. If closed techniques are used, evidence supports placing the closure off the midline. Diligent, long-term postoperative follow-up and careful attention to wound care are essential.

\section{ACKNOWLEDGMENT}

The authors gratefully acknowledge the editorial assistance of Maureen Rombeau, M.A.

\section{REFERENCES}

1. Søndenaa K, Andersen E, Nesvik I, Søreide JA. Patient characteristics and symptoms in chronic pilonidal sinus disease. Int J Colorectal Dis 1995;10(1):39-42

2. Akinci OF, Bozer M, Uzunköy A, Düzgün SA, Cokun A. Incidence and aetiological factors in pilonidal sinus among Turkish soldiers. Eur J Surg 1999;165(4):339-342

3. Mayo $\mathrm{OH}$. Observations on Injuries and Diseases of the Rectum. London: Burgess and Hill; 1833

4. Hodges RM. Pilo-nidal sinus. Boston Med Surg J 1880; 103:485-486

5. Buie LA. Jeep disease. South Med J 1944;37:103-109

6. Ballas K, Psarras K, Rafailidis S, Konstantinidis H, Sakadamis A. Interdigital pilonidal sinus in a hairdresser. J Hand Surg [Br] 2006;31(3):290-291

7. Bascom J, Bascom T. Failed pilonidal surgery: new paradigm and new operation leading to cures. Arch Surg 2002;137(10): 1146-1150, discussion 1151

8. Karydakis GE. New approach to the problem of pilonidal sinus. Lancet 1973;2(7843):1414-1415

9. Karydakis GE. Easy and successful treatment of pilonidal sinus after explanation of its causative process. Aust $\mathrm{N} \mathrm{Z} \mathrm{J}$ Surg 1992;62(5):385-389

10. Kitchen P. Pilonidal sinus - management in the primary care setting. Aust Fam Physician 2010;39(6):372-375

11. Akinci OF, Kurt M, Terzi A, Atak I, Subasi IE, Akbilgic O. Natal cleft deeper in patients with pilonidal sinus: implications for choice of surgical procedure. Dis Colon Rectum 2009;52(5):1000-1002

12. da Silva JH. Pilonidal cyst: cause and treatment. Dis Colon Rectum 2000;43(8):1146-1156

13. Solla JA, Rothenberger DA. Chronic pilonidal disease. An assessment of 150 cases. Dis Colon Rectum 1990;33(9): 758-761

14. Lee PJ, Raniga S, Biyani DK, Watson AJM, Faragher IG, Frizelle FA. Sacrococcygeal pilonidal disease. Colorectal Dis 2008;10(7):639-650, discussion 651-652

15. Hull TL, Wu J. Pilonidal disease. Surg Clin North Am 2002;82(6):1169-1185

16. Armstrong JH, Barcia PJ. Pilonidal sinus disease. The conservative approach. Arch Surg 1994;129(9):914-917, discussion 917-919

17. Odili J, Gault D. Laser depilation of the natal cleft-an aid to healing the pilonidal sinus. Ann R Coll Surg Engl 2002; 84(1):29-32

18. Nelson JM, Billingham RP. Pilonidal disease and hidradenitis suppurativa. In: Wolff BC, Fleshman JW, Beck DE, Pemberton JH, Wexner SD eds. The ASCRS Textbook of 
Colon and Rectal Surgery. New York, NY: Springer; 2007: 228-239

19. Karakayali F, Karagulle E, Karabulut Z, Oksuz E, Moray G, Haberal M. Unroofing and marsupialization vs. rhomboid excision and Limberg flap in pilonidal disease: a prospective, randomized, clinical trial. Dis Colon Rectum 2009;52(3): 496-502

20. Gips M, Melki Y, Salem L, Weil R, Sulkes J. Minimal surgery for pilonidal disease using trephines: description of a new technique and long-term outcomes in 1,358 patients. Dis Colon Rectum 2008;51(11):1656-1662, discussion 1662-1663

21. Bascom J. Pilonidal disease: long-term results of follicle removal. Dis Colon Rectum 1983;26(12):800-807

22. Bascom JU. Repeat pilonidal operations. Am J Surg 1987; 154(1):118-122

23. Senapati A, Cripps NP, Thompson MR. Bascom's operation in the day-surgical management of symptomatic pilonidal sinus. Br J Surg 2000;87(8):1067-1070

24. Al-Khamis A, McCallum I, King PM, Bruce J. Healing by primary versus secondary intention after surgical treatment for pilonidal sinus. Cochrane Database Syst Rev 2010; (1)CD006213

25. Bascom J, Bascom T. Utility of the cleft lift procedure in refractory pilonidal disease. Am J Surg 2007;193(5):606-609, discussion 609

26. Mahdy T. Surgical treatment of the pilonidal disease: primary closure or flap reconstruction after excision. Dis Colon Rectum 2008;51(12):1816-1822

27. Cihan A, Ucan BH, Comert M, Cesur A, Cakmak GK, Tascilar O. Superiority of asymmetric modified Limberg flap for surgical treatment of pilonidal disease. Dis Colon Rectum 2006;49(2):244-249

28. Mentes O, Bagci M, Bilgin T, Ozgul O, Ozdemir M. Limberg flap procedure for pilonidal sinus disease: results of 353 patients. Langenbecks Arch Surg 2008;393(2): 185-189

29. Nursal TZ, Ezer A, Calikan K, Törer N, Belli S, Moray G. Prospective randomized controlled trial comparing $\mathrm{V}-\mathrm{Y}$ advancement flap with primary suture methods in pilonidal disease. Am J Surg 2010;199(2):170-177

30. Fazeli MS, Adel MG, Lebaschi AH. Comparison of outcomes in Z-plasty and delayed healing by secondary intention of the wound after excision of the sacral pilonidal sinus: results of a randomized, clinical trial. Dis Colon Rectum 2006;49(12):1831-1836

31. McCallum I, King PM, Bruce J. Healing by primary versus secondary intention after surgical treatment for pilonidal sinus. Cochrane Database Syst Rev 2007;(4)CD006213

32. Søndenaa K, Nesvik I, Gullaksen FP, et al. The role of cefoxitin prophylaxis in chronic pilonidal sinus treated with excision and primary suture. J Am Coll Surg 1995;180(2):157-160

33. Humphries AE, Duncan JE. Evaluation and management of pilonidal disease. Surg Clin North Am 2010;90(1):113-124

34. Dogru O, Camci C, Aygen E, Girgin M, Topuz O. Pilonidal sinus treated with crystallized phenol: an eight-year experience. Dis Colon Rectum 2004;47(11):1934-1938

35. Aygen E, Arslan K, Dogru O, Basbug M, Camci C. Crystallized phenol in nonoperative treatment of previously operated, recurrent pilonidal disease. Dis Colon Rectum 2010; 53(6):932-935

36. Rudkin GH, Miller TA. Growth factors in surgery. Plast Reconstr Surg 1996;97(2):469-476

37. Leitner GC, Gruber R, Neumüller J, et al. Platelet content and growth factor release in platelet-rich plasma: a comparison of four different systems. Vox Sang 2006;91(2):135-139

38. Spyridakis M, Christodoulidis G, Chatzitheofilou C, Symeonidis D, Tepetes K. The role of the platelet-rich plasma in accelerating the wound-healing process and recovery in patients being operated for pilonidal sinus disease: preliminary results. World J Surg 2009;33(8):1764-1769

39. McGuinness JG, Winter DC, O'Connell PR. Vacuumassisted closure of a complex pilonidal sinus. Dis Colon Rectum 2003;46(2):274-276

40. Lynch JB, Laing AJ, Regan PJ. Vacuum-assisted closure therapy: a new treatment option for recurrent pilonidal sinus disease. Report of three cases. Dis Colon Rectum 2004;47(6): 929-932 